\title{
EDUKASI ZAT ADITIF PADA JAJANAN SEKOLAH DARI PERSPEKTIF KESEHATAN
}

\author{
Mega Fia Lestari \\ Akademi Komunitas Industri Manufaktur Bantaeng \\ megafialestari@kemenperin.go.id
}

\begin{abstract}
Abstrak
Kehadiran jajanan dengan warna yang menarik dan cita rasa yang membangkitkan selera membuat para siswa lebih memilih jajan di sekolah dibandingkan membawa bekal dari rumah. Sedangkan jajanan dengan warna yang mencolok dan rasa yang lezat berpotensi mengandung zat aditif yang memiliki dampak buruk bagi kesehatan, apalagi jika dikonsumsi secara berlebihan. Oleh karena itu, edukasi tentang zat aditif sangat penting untuk dilakukan agar para siswa lebih selektif saat membeli jajanan. Kegiatan edukasi ini dilaksanakan kepada siswa SMK se-Kabupaten Bantaeng, Provinsi Sulawesi Selatan dengan metode ceramah dan diskusi menggunakan media powerpoint dengan memasukkan berbagai contoh jajanan yang biasa mereka temukan sehari-hari. Hasilnya menunjukkan bahwa secara umum siswa belum mengetahui pengertian, jenis dan dampak negatif zat aditif yang sering ditambahkan pada jajanan. Para siswa cenderung membeli makanan hanya berdasarkan warna yang menarik dan rasa yang nikmat tanpa memikirkan dampak buruk dari jajanan tersebut. Implikasi dari kegiatan ini adalah siswa mampu memahami dan mengidentifikasi zat aditif apa yang digunakan pada jajanan yang biasa mereka konsumsi berdasarkan materi yang telah dipaparkan sebelumnya. Selain itu, para siswa telah sadar bahwa kebiasaan membawa bekal dari rumah sangat baik untuk menjaga kesehatan.
\end{abstract}

Kata Kunci : Jajanan, Kesehatan, Zat aditif.

\section{PENDAHULUAN}

Perilaku jajan baik di kantin ataupun di luar sekolah telah menjadi rutinitas bagi siswa sekolah setiap harinya. Dengan adanya uang saku yang diberikan orang tua, maka mereka dengan mudahnya membeli jajanan dengan hanya mementingkan rasa yang lezat, gurih, sedap dipandang dan harganya yang murah. Mereka umumnya tidak memperhatikan apakah makanan tersebut sehat bagi tubuhnya atau justru dapat membahayakan kesehatannya.

Jajanan yang dijual umumnya menggunakan zat aditif agar jajanan tersebut menarik perhatian dan disukai oleh anak-anak serta tahan lama. Zat aditif merupakan senyawa/bahan kimia yang dicampurkan pada produk pangan guna meningkatkan cita rasa, warna, aroma, tekstur, dan untuk mengawetkan jajanan tersebut. Zat aditif dicampurkan pada jajanan baik dalam proses pengolahan, penyimpanan, maupun pengemasannya (Rorong \& Wilar, 2019). Jenis zat aditif yang biasa ditambahkan pada jajanan misalnya penyedap rasa, pemberi aroma, pewarna, pemanis, pengawet, zat pengasam, antioksidan, pengemban, pemutih, dan zat pemucat (Karunia, 2013). Zat aditif menurut Peraturan Menteri Kesehatan dikenal sebagai Bahan Tambahan Pangan (BTP). Zat aditif yang ditambahkan pada produk pangan tidak boleh melebihi Acceptable Daily Intake (ADI) yakni jumlah maksimal zat aditif dalam $\mathrm{mg} / \mathrm{kg}$ berat tubuh

$$
\text { Pangan dan Kesehatan }
$$


yang bisa dikonsumsi setiap hari tanpa mengakibatkan gangguan kesehatan. Informasi mengenai zat aditif pada produk pangan dapat diamati pada label komposisi (Adrian, 2020).

Pemerintah melalui Peraturan Menteri Kesehatan Republik Indonesia Nomor 033 Tahun 2012 mengatur segala hal tentang BTP dimulai dari jenis BTP yang diperbolehkan hingga kadar penggunaan BTP pada pangan. Pada Pasal 4 Ayat (1) disampaikan bahwa "Jenis BTP yang diizinkan pada golongan sebagaimana dimaksud dalam Pasal 3 Ayat (1) tercantum dalam Lampiran I yang merupakan bagian tidak terpisahkan dari Peraturan Menteri ini”. Demikian pada Pasal 5 Ayat (1) disebutkan bahwa "BTP hanya boleh digunakan tidak melebihi batas maksimum penggunaan dalam kategori pangan" (Kementerian Kesehatan Republik Indonesia, 2020).

Zat aditif pada produk pangan terbagi atas zat aditif alami dan zat aditif sintesis. Zat aditif alami adalah segala zat tambahan pada makanan/minuman yang berasal dari tumbuhan, hewan, maupun mineral alam, misalnya warna kuning dapat diperoleh dari kunyit. Sedangkan zat aditif sintesis adalah zat aditif yang diperoleh dari berbagai campuran bahan dengan komposisi tertentu, misalnya Tartrazin yang merupakan pewarna makanan sintesis yang berwarna kuning (Adrian, 2020).

Zat aditif umumnya aman dikonsumsi terutama zat aditif alami. Namun, jenis zat aditif yang saat ini umum digunakan oleh produsen adalah zat aditif buatan dikarenakan harganya yang murah dan memberikan efek yang sangat kuat pada produk makanan maupun minuman sehingga jika dikonsumsi secara berlebihan akan berdampak buruk terhadap kesehatan. Misalnya Monosodium Glutamate (MSG) yang dikenal sebagai micin/vetsin digunakan sebagai penyedap rasa karena memberi rasa gurih pada makanan misalnya pada keripik kentang, bakso, dan bumbu mie instan. Menurut Andini (Andini, 2020) dan Nareza (Nareza, 2020), terlalu banyak mengonsumsi vetsin diprediksi penyebab utama timbulnya sakit kepala disertai mual yang merupakan gejala Chinese Restaurant Syndrome serta menyebabkan kerusakan sel saraf dan gangguan fungsi otak sehingga timbul penyakit Alzheimer, Parkinson dan stroke.
Ditambah pula dengan adanya produsen nakal yang menggunakan zat aditif buatan yang tidak direkomendasikan oleh Menteri Kesehatan RI sebagai BTP. Misalnya formalin yang berfungsi untuk mengawetkan mayat ditemukan terkandung dalam ikan asin, mie basah, dan takjil di daerah Jakarta (Arumsari et al., 2017) (Faiz, 2018), Purwokerto (Eviyanti, 2019), dan Pekanbaru (Yulisa et al., 2014). Begitupun Rhodamin B yang merupakan pewarna tekstil digunakan sebagai pewarna kerupuk dan saus sambal di Denpasar (Laksmita et al., 2018) dan Yogyakarta (Setiawan, 2019). Menurut BPOM (Badan Pom Republik Indonesia, 2008), jika formalin tertelan mengakibatkan pusing, muntah, dan gangguan pada saluran perncernaan. Sedangkan menurut WHO dalam Sentra Informasi Keracunan Nasional (Sentra Informasi Keracunan Nasional, 2012), terlalu sering mengonsumsi Rhodamin B mengakibatkan gangguan pada fungsi ginjal dan hati.

Sebanyak 10.429 contoh Pangan Jajanan Anak Sekolah (PJAS) diuji oleh BPOM dari berbagai wilayah di Indonesia sejak tahun 20092014, hasilnya diperoleh data bahwa sebanyak $76,18 \%$ jajanan termasuk kategori sehat sedangkan $23,82 \%$ termasuk kategori tidak sehat. Bakso, minuman sirup berwarna, agar-agar, dan minuman dingin termasuk sebagai jajanan tidak sehat yang paling banyak dijumpai. Penyebabnya dikarenakan mengandung kadar BTP, cemaran logam, dan mikrobilogis yang melebihi ambang batas maksimum (Pusat Data dan Informasi Kementerian Kesehatan Republik Indonesia, 2015).

Siswa sekolah sebagai konsumen utama PJAS merupakan generasi penerus bangsa Indonesia dimasa yang akan datang oleh karenanya edukasi keaman pangan menjadi salah satu upaya agar siswa sekolah mampu memahami dan menerapkan perilaku keaman pangan secara konsisten. Menurut Asfawi dan Ainunrahmah (Asfawi \& Ainurahmah, 2012), apabila anak diberi pemahaman/pengetahuan tentang BTP, maka anak akan membiasakan diri untuk memilih jajanan yang sehat. Oleh karena itu, kegiatan Edukasi Zat Aditif Pada Jajanan Sekolah Dari Perspektif Kesehatan sangat penting untuk dilakukan pada siswa sekolah khsususnya siswa SMK se-Kab. Bantaeng Provinsi Sulawesi Selatan agar perilaku mereka dapat berubah dari jajan sembarangan menjadi jajan yang 
lebih sehat termasuk membiasakan diri untuk membawa bekal dari rumah.

\section{METODE}

Bentuk kegiatan pada pengabdian masyarakat ini berupa penyuluhan mengenai Zat Aditif Pada Jajanan Sekolah Dari Perspektif Kesehatan dengan menggunakan media powerpoint, video dan leaflet. Penyuluhan diberikan oleh pelaksana $\mathrm{PkM}$ didampingi mahasiswa, dilaksanakan selama sehari di kampus Akademi Komunitas Industri Manufaktur Bantaeng yang diikuti oleh perwakilan siswa SMK se-Kab. Bantaeng Provinsi Sulawesi Selatan.

Isi penyuluhan meliputi pengertian zat aditif, jenis zat aditif, contoh produk yang mengandung zat aditif, jenis bahan berbahaya yang biasa ditambahkan pada makanan, ciri-ciri produk yang mengandung bahan berbahaya, dan dampak buruk mengonsumsi zat aditif berlebih bagi kesehatan. Selanjutnya ditampilkan berbagai contoh kasus tentang penemuan bahan berbahaya yang dicampurkan pada suatu produk pangan yang terjadi di berbagai wilayah di Indonesia. Tujuannya agar kegiatan edukasi ini betul-betul bisa dipahami dan tersimpan baik di memori para siswa tersebut. Setelah materi disampaikan, kemudian dilaksanakan diskusi antara pemateri dengan siswa SMK dan sebelum kegiatan berakhir, dilaksanakan pemberian door prize bagi peserta yang memberikan pertanyaan terbaik dilanjutkan pengisian Kuosioner Kepuasan Kegiatan untuk dapat mengevaluasi kegiatan PkM edukasi zat aditif ini.

\section{HASIL DAN PEMBAHASAN}

Pengabdian Kepada Masyarakat (PkM) yang berjudul Edukasi Zat Aditif Pada Jajanan Sekolah Dari Perspektif Kesehatan dilaksanakan pada Jumat, 8 November 2019 bertempat di ruang serbaguna Akademi Komunitas Industri Manufaktur Bantaeng. Peserta pelatihan sebanyak 45 orang berasal dari SMK Negeri 5 Bantaeng, SMK Negeri 3 Bantaeng dan SMK Negeri 2 Bantaeng. Provinsi Sulawesi Selatan. Tim pelaksana PkM terdiri atas pemateri yakni Mega Fia Lestari, M.Sc dan 2 orang mahasiswa sebagai panitia. Kegiatan penyuluhan dimulai pada pukul 09.00 WITA hingga 12.00 WITA. Peserta terlebih dahulu melakukan registrasi dengan mengisi daftar hadir dan pembagian snack. Kegiatan edukasi diawali dengan perkenalan diri peserta dan pemateri lalu dilanjutkan penjelasan tentang maksud dan tujuan dilaksanakannya PkM edukasi zat aditif ini.

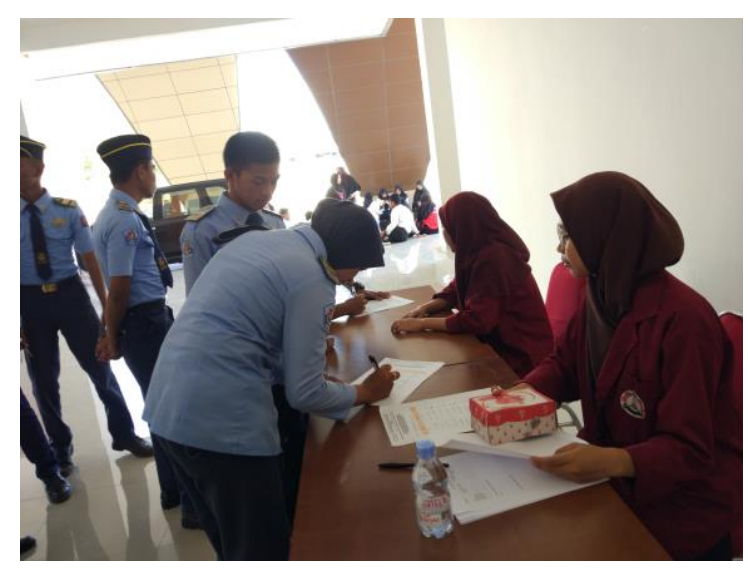

Gambar 1. Registrasi Peserta PkM

Materi yang dipaparkan pada kegiatan edukasi zat aditif ini terbagi atas dua bagian yakni (1) zat aditif yang diijinkan oleh Kementerian Kesehatan untuk ditambahkan pada produk pangan; dan (2) bahan berbahaya yang dicampurkan pada produk pangan. Pada materi bagian pertama, siswa diedukasi mengenai apa itu zat aditif, jenis zat aditif apa saja yang dicampurkan pada produk pangan dan aman menurut Kementerian Kesehatan, bagaimana ciri-ciri produk pangan yang mengandung zat aditif, berapa kadar maksimum zat aditif yang bisa dikonsumsi oleh tubuh dan bagaimana dampak terhadap tubuh jika mengonsumsi zat aditif secara berlebihan.

Pada materi bagian kedua, siswa diedukasi bahwa ada produsen nakal yang tidak menggunakan zat aditif sesuai rekomendasi Kementerian Kesehatan melainkan menggunakan bahan berbahaya yang seharusnya tidak masuk ke dalam tubuh. Bahan berbahaya didefinisikan sebagai senyawa kimia yang dapat mengakibatkan gangguan terhadap kesehatan baik dalam bentuk tunggal ataupun campuran sesuai dengan Peraturan Menteri Kesehatan No.472/Menkes/Per/V/1996 
tentang Pengamanan Bahan Berbahaya Bagi Kesehatan (Badan POM, 2020). Produsen menggunakan bahan berbahaya tersebut dikarenakan ketidaktahuannya dan harganya yang murah.
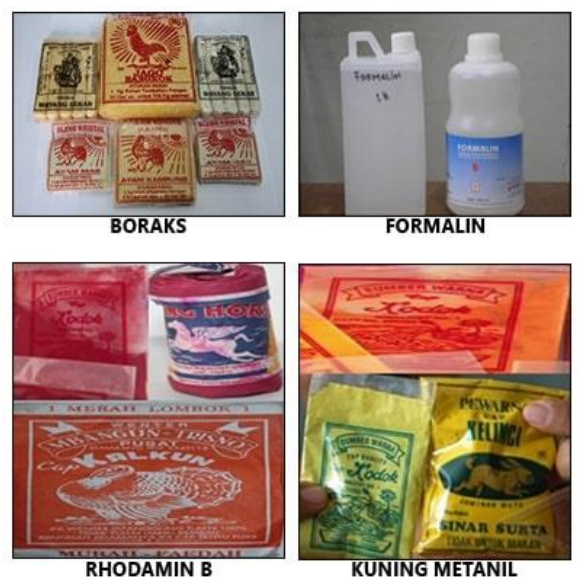

Sumber: (Badan POM, 2020)

Gambar 2. Bahan Berbahaya Yang Sering Ditemukan Pada Produk Pangan

Menurut BPOM (Badan POM, 2020), ada 4 bahan berbahaya yang paling sering ditemukan disalahgunakan dalam produk pangan yakni boraks, formalin, Rhodamin B, dan Methanil Yellow. (1) Boraks dikenal dengan bleng/pijer yang biasa digunakan sebagai campuran pupuk tanaman ditemukan pada produk mie basah, bakso, lontong, dan kerupuk gendar. Boraks membuat tekstur makanan lebih kenyal, mengkilap, tidak mudah putus, dan lebih renyah. (2) Formalin yang digunakan untuk mengawetkan mayat ditemukan pada produk pangan seperti tahu, mie basah, ayam potong, ikan segar dan ikan asin. Formalin digunakan karena membuat tekstur makanan tidak mudah hancur dan lebih tahan lama. (3) Rhodamin B yang menghasilkan warna merah dan (4) Methanil Yellow yang menghasilkan warna kuning merupakan pewarna tekstil dan cat namun ditemukan pada produk kerupuk, terasi, sirup, tahu, dan mie basah yang berwarna merah dan kuning, Ciri-cirinya adalah warna merah dan kuning dari produk tersebut yang sangat terang dan mencolok.

Setelah materi dipaparkan, selanjutnya menampilkan berbagai berita online dari website terpecaya mengenai kasus-kasus penemuan penggunaan bahan berbahaya pada produk pangan khususnya pada jajanan sekolah di berbagai wilayah di Indonesia. Kemudian menampilkan video investigasi tentang bagaimana bahan berbahaya dicampurkan pada produk pangan. Tujuannya agar kegiatan ini betul-betul dapat mengedukasi para siswa untuk lebih menjaga kesehatan dengan cara memperhatikan apa yang akan masuk ke dalam tubuh mereka.

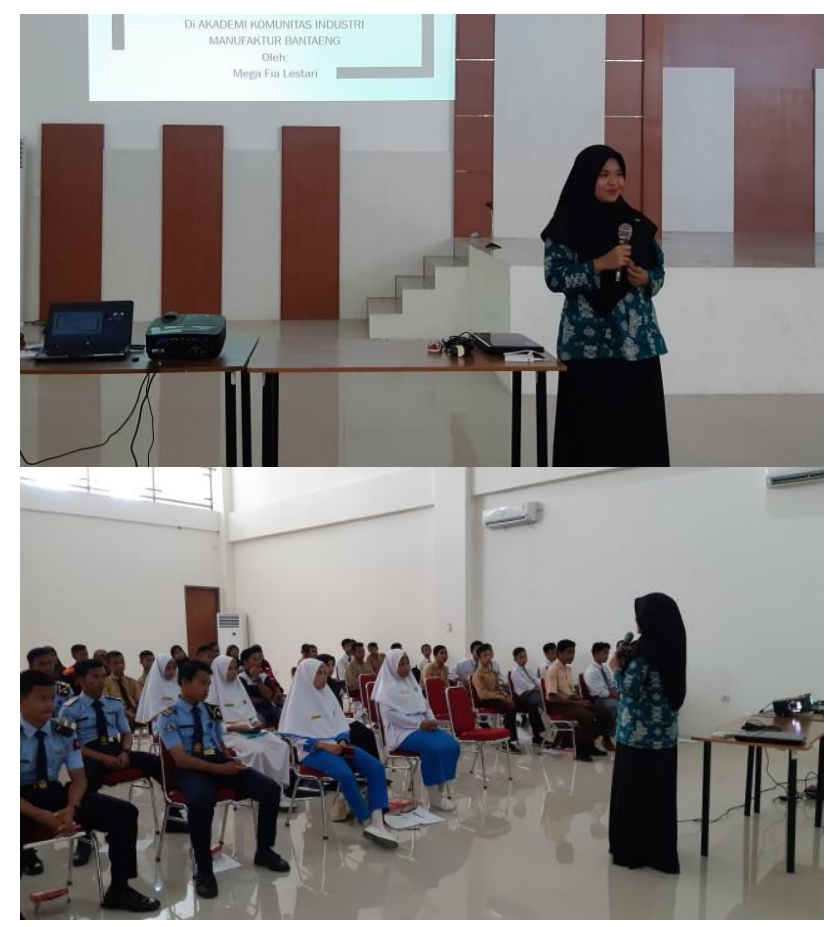

Gambar 3. Pemaparan Materi Zat Aditif

Menurut Pusat Data dan Informasi Kementerian Kesehatan (Pusat Data dan Informasi Kementerian Kesehatan Republik Indonesia, 2015), ada 5 tips yang bisa dilakukan oleh siswa dalam menjalankan praktek keamanan pangan, yaitu (1) mengenali pangan yang termasuk kategori aman: artinya kenali karakteristik pangan yang mengandung zat aditif melebihi batas maksimum serta bahan berbahaya. (2) Membeli pangan yang aman: artinya pangan dijual oleh pedagang yang sehat, berpenampilan bersih dan dagangannya juga bersih, serta membeli pangan yang telah matang. (3) Membaca label pada kemasan pangan; artinya memperhatikan secara saksama kandungan senyawa kimiawi yang terdapat pada produk pangan. (4) Menjaga kebersihan: artinya selalu mencuci tangan 
terlebih dahulu sebelum makan maupun minum. (5) Mencatat apa yang ditemui: artinya laporkan jika menemui penyimpangan terhadap praktik keamanan pangan baik di sekolah maupun di tempat lainnya. Laporan ditujukan kepada BPOM melalui notifikasi elektronik (e-notifikasi) yang merupakan sistem informasi antara sekolah dengan BPOM guna menginformasikan secara cepat terkait jajanan sekolah baik yang termasuk kategori aman maupun yang berbahaya.

Selama kegiatan PkM dilaksanakan, para siswa tampak sangat antusias dalam memperhatikan materi dan video yang dipaparkan. Mereka sangat bersemangat untuk mengajukan berbagai jenis pertanyaan saat sesi diskusi dimulai. Jenis pertanyaan yang paling banyak ditanyakan apakah produk $\mathrm{A} / \mathrm{B} / \mathrm{C}$ yang sering mereka konsumsi mengandung zat aditif yang aman atau malah mengandung bahan berbahaya. Mereka juga menanyakan bagaimana cara mengenali secara cepat bahwa produk tersebut aman atau malah berbahaya jika dikonsumsi. Selain itu, dari hasil diskusi dengan peserta diketahui bahwa secara umum, mereka sama sekali belum pernah mendengar apa itu zat aditif dan jenis zat aditif sehingga kegiatan ini terasa kebermanfaatannya bagi peserta dalam hal menambah wawasannya. Para siswa juga berkomitmen untuk lebih berhatihati ketika jajan dengan memperhatikan apakah jajanan tersebut baik atau buruk bagi kesehatan bila dikonsumsi.

Pada akhir kegiatan edukasi, dipilih 3 siswa yang mengajukan pertanyaan paling menarik sebagai pemenang untuk mendapatkan door prize. Kemudian, para mahasiswa yang menjadi panitia membagikan lembar Kuosioner Kepuasan Kegiatan untuk diisi oleh peserta guna mengetahui bagaimana pelaksanaan PkM ini dan untuk pengembangan pada pelaksanaan PkM berikutnya. Indikator pada lembar kuesioner tersebut mengenai (1) konten materi, (2) penyajian/tampilan materi, (3) cara penyampaian pemateri, (4) akomodasi dan (5) saran. Berdasarkan hasil analisis kuosioner diketahui bahwa secara umum indikator 1-4 memperoleh penialaian baik/penting. Artinya para siswa puas terhadap pelaksanaan PkM mengenai edukasi zat aditif ini. Namun, terdapat saran yang akan menjadi perbaikan PkM berikutnya bahwa dikarenakan peserta siswa SMK berasal dari berbagai konsentrasi yang berbeda yakni Farmasi, Kesehatan, Teknik Otomotif, dan Pelayaran maka materi PkM berikutnya sebaiknya menyesuaikan terhadap jurusan para siswa SMK tersebut sehingga dapat mengembangkan pengetahuan sesuai bidang yang mereka tekuni.

\section{KESIMPULAN}

Berdasarkan kegiatan edukasi yang telah dilakukan dapat disimpulkan bahwa kegiatan ini berhasil menambah wawasan siswa terkait zat aditif dan bahan berbahaya yang biasa dicampurkan oleh produsen pada suatu produk pangan dan bagaimana dampaknya terhadap kesehatan bila kita mengonsumsinya secara berlebihan. Hal ini terbukti dari antusiasme mereka dalam menyimak meteri yang disajikan dan keaktifan peserta saat sesi diskusi dilaksanakan.

\section{UCAPAN TERIMAKASIH}

Ucapan terimakasih disampaikan kepada Akademi Komunitas Industri Manufaktur Bantaeng yang telah membiayai penuh kegiatan PkM Tahun 2019 serta kepada Kepala Sekolah SMK Negeri 5 Bantaeng, SMK Negeri 3 Bantaeng dan SMK Negeri 2 Bantaeng yang telah mengutus perwakilan siswa untuk menjadi peserta pada kegiatan PkM edukasi zat aditif ini.

\section{REFERENSI}

Adrian, K. (2020). Jenis Zat Aditif pada Makanan, Kegunaan dan Efek Sampingnya. Alodokter.Com. https://www.alodokter.com/memahami-zataditif-pada-makanan-kegunaan-serta-efeksampingnya. Diakses pada 10 September 2020.

Andini, W. C. (2020). 8 Zat Aditif Pada Makanan Serta Efeknya untuk Kesehatan. Hellosehat.Com. https://hellosehat.com/hidupsehat/nutrisi/efek-zat-aditif-pada-

$$
\text { Pangan dan Kesehatan }
$$


makanan/\#gref. Diakses pada 10 September 2020.

Arumsari, G. P., Krianto, T., \& Wispriyono, B. (2017). Perilaku Penggunaan Formalin Pada Pedagang Dan Produsen Mie Basah Dan Tahu di Provinsi DKI Jakarta. Jurnal Kesehatan Masyarakat Andalas, 11(1), 39-48.

Asfawi, S., \& Ainurahmah, S. (2012). Analisis Perilaku Siswa Terhadap Kebiasaan Jajan Di Sekitar Sekolahan. Jurnal Visikes, 11(1), 1825.

Badan POM. (2020). Bahan Berbahaya. Badan Pengawas Obat Dan Makanan (BPOM) RI. http://puspaman.pom.go.id/bahan-berbahaya.

Diakses pada 11 September 2020.

Badan Pom Republik Indonesia. (2008). Formalin (Larutan Formaldehid). In pom.go.id. Badan Pom Republik Indonesia. http://www.pom.go.id/files/formalin.pdf.

Diakses pada 10 September 2020.

Eviyanti. (2019). Petugas Temukan Sampel Makanan Mengandung Pewarna Tekstil di Pasar Manis Purwokerto. PikiranRakyat.Com. https://www.pikiranrakyat.com/nasional/pr-01312538/petugastemukan-sampel-makanan-mengandungpewarna-tekstil-di-pasar-manis-purwokerto. Diakses pada 11 September 2020.

Faiz, D. (2018). Takjil Mengandung Formalin Marak di Sejumlah Daerah. Cnnindonesia.Com.

https://www.cnnindonesia.com/nasional/2018 0606110543-20-303892/takjil-mengandungformalin-marak-di-sejumlah-daerah. Diakses pada 11 September 2020.

Karunia, F. B. (2013). Kajian Penggunaan Zat Adiktif Makanan (Pemanis dan Pewarna) pada Kudapan Bahan Pangan Lokal di Pasar Kota Semarang. Foof Science and Culinary Journal, 2(2), 72-78.

Kementerian Kesehatan Republik Indonesia. (2020). Website Direktorat Jenderal
Kesehatan Masyarakat. Kementerian Kesehatan Republik Indonesia. http://www.kesmas.kemkes.go.id/portal/konte n//. Diakses pada 10 September 2020.

Laksmita, A. S., Widayanti, N. P., \& Refi, M. A. F. (2018). Identifikasi Rhodamin B Dalam Saus Sambal Yang Beredar Di Pasar Tradisional Dan Modern Kota Denpasar. Jurnal Media Sains, 2(1), 41-46.

Nareza, M. (2020). Ini Dampak Konsumsi Micin secara Berlebih. Alodokter.Com. https://www.alodokter.com/efek-konsumsimicin-berlebihan-ini-dampaknya-bagi-

kesehatan\#: :text=Kerusakan sel saraf\&text=Bahkan disebutkan pula bahwa MSG,\%2C penyakit Parkinson\%2C dan stroke. Diakses pada 10 September 2020.

Pusat Data dan Informasi Kementerian Kesehatan Republik Indonesia. (2015). Situasi Pangan Jajanan Anak Sekolah (pp. 1-8). https://doi.org/ISSN 2442-7659.

Rorong, J. A., \& Wilar, W. F. (2019). Studi Tentang Aplikasi Zat Aditif Pada Makanan Yang Beredar Di Pasaran Kota Manado. Techno Science Journal, 1(2), 39-52.

Sentra Informasi Keracunan Nasional. (2012). Bahaya Rhodamin B sebagai Pewarna pada Pangan. Badan Pengawas Obat Dan Makanan (BPOM) RI, 1-3. http://ik.pom.go.id. Diakses pada 12 September 2020.

Setiawan, S. D. (2019). BPOM DIY Temukan Makanan Berbahaya yang Dikamuflase. Nasional.Republika.Co.Id.

https://nasional.republika.co.id/berita/nasional/ daerah/prnpi3459/bpom-diy-temukanmakanan-berbahaya-yang-dikamuflase. Diakses pada 10 September 2020.

Yulisa, N., Asni, A., \& Azrin, M. (2014). Uji Formalin Pada Ikan Asin Gurami Di Pasar Tradisional. Jom FK, 1(2), 1-12. 